Research Article

\title{
Graphitization of Coconut Shell Charcoal for Sulfonated Mesoporous Carbon Catalyst Preparation and Its Catalytic Behavior in Esterification Reaction
}

\author{
F. Fahmi, W. Widiyastuti, Heru Setyawan* \\ Department of Chemical Engineering, Institut Teknologi Sepuluh Nopember, Kampus ITS Sukolilo, \\ Surabaya 60111, Indonesia
}

Received: $7^{\text {th }}$ May 2020; Revised: 25th June 2020; Accepted: $26^{\text {th }}$ June 2020;

Available online: $30^{\text {th }}$ July 2020; Published regularly: August 2020

\begin{abstract}
Here, we reported the utilization of coconut shell charcoal used for solid acid catalysts and its performance in the esterification reaction of acetic acid and methanol. The graphitization of coconut shell charcoal was carried out by the calcination and $\mathrm{KOH}$ activation at the temperature of $400{ }^{\circ} \mathrm{C}$ for an hour and continued at the temperature of $800^{\circ} \mathrm{C}$ for an hour under nitrogen flow resulted in graphitic carbon. The effect of the addition of $\mathrm{KOH}$ activation was observed by varied the weight ratio of coconut shell charcoal as raw material (RM) and $\mathrm{KOH}$. The selected weight ratio of RM:KOH was 1:1, 1:2, and 1:4. The resulted graphitic carbon was sulfonated by heating with the sulfuric acid to obtain a solid acid catalyst. The sulfonic time was evaluated for 5 and 10 hours. The generated particles were characterized to examine the morphology, the crystallinity, the specific surface area, the chemical bonding, and the ionic capacity using Scanning Electron Microscopy (SEM), X-Ray diffraction (XRD), nitrogen gas absorption-desorption, Fourier Transform Infrared Spectroscopy (FTIR), and titration method, respectively. The best condition for graphitization of raw material is the use of RM:KOH $=1: 4$, resulting in the highest surface area reaching $1259.67 \mathrm{~m}^{2} / \mathrm{g}$ and the most dominant of the sulfonic group of $-\mathrm{SO}_{3}$ bond. Furthermore, increasing the sulfonating time from 5 to 10 hours led to the increase of the yield of esterification reaction from $85 \%$ to $96.57 \%$ for graphite synthesized using RM:KOH $=1: 4$. Copyright (C) 2020 BCREC Group. All rights reserved
\end{abstract}

Keywords: Solid Acid Catalyst; Sulfonating Time; Esterification; Graphitic Carbon; Ionic Capacity

How to Cite: Fahmi, F., Widiyastuti, W., Setyawan, H. (2020). Graphitization of Coconut Shell Charcoal for Sulfonated Mesoporous Carbon Catalyst Preparation and Its Catalytic Behavior in Esterification Reaction. Bulletin of Chemical Reaction Engineering \& Catalysis, 15(2), 538-544

(doi:10.9767/bcrec.15.2.7745.538-544)

Permalink/DOI: https://doi.org/10.9767/bcrec.15.2.7745.538-544

\section{Introduction}

Esterification of acetic acid with methanol producing methyl acetate is widely used as a solvent in many commodities such as glues, per-

\footnotetext{
* Corresponding Author.

E-mail: sheru@chem-eng.its.ac.id (H. Setyawan); Telp: +62-31-5946240, Fax: +62-31-5999282
}

fumes, resins, plasticizers, and paint polish removers. Methyl acetate is also used as a solvent for extractions and production of coating materials, nitro-cellulose, cellulose acetate, and cellulose ethers [1,2]. The acid catalyst is used to accelerate the esterification reaction that can be homogenous or heterogeneous catalysts. The use of homogenous catalysts is usually low cost and high catalytic activity because of the same 
phase between catalyst, reactant, and product [3]. However, the limitation of homogenous catalysts is reactor corrosion generation, environmental pollution, and the difficulties in catalyst recycle. In addition, the recovery of the homogeneous catalyst from the reaction medium is high cost and not an easy process. The advantages of heterogeneous catalysts are easily separated from the reaction media, recycle ability, improved selectivity, and reducing process stages and wastes $[4,5]$. Nevertheless, the preparation of heterogeneous catalysts is also not easy because the catalytic activity is enhanced by the number of active sites as a result of a combination of the higher surface area and higher porosity [6,7].

The performance of various heterogeneous catalysts for the esterification reaction has been reported. The use of various commercial ion exchange resins as the catalyst and commercial solid acid catalysts for the esterification reaction has been evaluated [1,8-10]. It is also reported that the catalytic activity of carbon-based solid acid catalysts is five times higher than that of a kind of ion exchange resin catalyst for oleic acid esterification [11].

Graphene oxide processed through the oxidation of natural graphite powder was used as a catalyst for the esterification reaction of acetic acid with methanol, biodiesel production from microalgae, and diindolyl-oxindole derivatives synthesis [12-15]. The activity of the catalyst was enhanced by grafting the active sulfate groups on its surface. The sulfonated ordered mesoporous carbon-based solid acid using sucrose as carbon source exhibited yield at around $90 \%$ for esterification reaction of free fatty acids [16,17] and transesterification of fatty acid methyl esters [18] in waste frying oil. Carbonization of glucose and starch mixture and B-cyclodextrin to generate solid acid catalyst was also reported having the highest esterification activity at certain condition process $[19,20]$. The sulfonated carbon base catalysts from glucose revealed a stable condition even at the temperature of $400{ }^{\circ} \mathrm{C}$ [21]. The waste utilization of rice husk and glycerol as sulfonated carbons used for solid acid catalysts were also reported for the esterification reaction [22,23]. The sulfonated coal-based heterogeneous acid catalyst claimed that it can reach $97 \%$ acid reduction efficiency by optimizing the carbonization and sulfonating temperatures [24]. Besides, the sulfonated carbons from the palm kernel shell also showed higher activity than the commercial acid resins for cellobiose hydrolysis reactions [25].
Here, we reported the utilization of coconut shell charcoal that activated using potassium hydroxide, calcined under nitrogen flow, and then sulfonated with sulfuric acid that resulted in sulfonated mesoporous graphitization carbon catalyst. The effects of potassium hydroxide addition and the duration of the sulfonating process on the characteristics of the particles were studied. Furthermore, the ion capacity and the catalyst activity in the acetic acid esterification with ethanol were examined.

\section{Materials and Methods}

\subsection{Materials and Chemicals}

Coconut shell charcoal was obtained from CV. Atma Multidaya Makmur, Indonesia. The potassium hydroxide (purity $85 \%$, Merck) and the sulfuric acid (purity 98\%) were used as the activated agent and as the sulfonating agent, respectively. The $20 \%$ of sulfuric acid was used to eliminate the contaminant in the generated graphite. Chloride acid and sodium hydroxide were used for ionic capacity determination. Nitrogen gas (99.99\%, PT. Aneka Gas) was used as an inert carrier gas in the graphitization process. Demineralized water was used as a washing agent and dilution process.

\subsection{Catalyst Preparation}

Firstly, the graphite particles were prepared. Coconut shell charcoal was crushed and sifted through a 75 mesh sieve. Then, the raw material of coconut shell charcoal powder (RM) was mixed into the crushed potassium hydroxide $(\mathrm{KOH})$ with RM:KOH weight ratio of $1: 1$, 1:2, and 1:4. The samples laid on the combustion boat were calcined in a tubular furnace (Thermo Scientific Lindberg, Germany, inside diameter of tube $2.54 \mathrm{~cm}$ and length $30 \mathrm{~cm}$ ) at the temperature of $400{ }^{\circ} \mathrm{C}$ for an hour and continued at the temperature of $800{ }^{\circ} \mathrm{C}$ for an hour under nitrogen flow. After the temperature of samples was the same as the room temperature, each sample was soaked with $20 \%$ sulfuric acid for 45 minutes. In the next step, each sample was filtered and dried in an oven at a temperature of $80^{\circ} \mathrm{C}$ for 18 hours.

Hereafter, the sulfonated graphite was prepared by soaking the graphite in concentrated sulfuric acid (98\%) in which a gram of graphite required $25 \mathrm{~mL}$ sulfuric acid at a temperature of $150{ }^{\circ} \mathrm{C}$. The sulfonating duration was 5 and 10 hours. Next, the sulfonated graphite particles were allowed to decrease the temperature up to the room temperature at around $30{ }^{\circ} \mathrm{C}$ and then washed with demineralized water. Fi- 
nally, the samples were dried in an oven at a temperature of $80{ }^{\circ} \mathrm{C}$ for 18 hours. The sulfonated graphite samples were named GxSy (x $=\mathrm{KOH}$ weight per weight $\mathrm{RM}, \mathrm{y}=$ sulfonating duration).

\subsection{Particles Characterization}

The crystallinity of catalysts was analyzed using X-Ray diffraction (XRD, PanAnalytical X'Pert MPD System). Scanning Electron Microscopy (SEM, FEI Inspect S50) was used to analyze the surface morphology of the catalyst. The chemical bonding of the catalysts was studied using Fourier Transform Infrared Spectroscopy (FTIR, Nicolet iS10). The specific surface area, pore size, and pore volume were measured using nitrogen gas absorptiondesorption (Nova 1200e, Quantachrome).

\subsection{Catalyst Performance Examination}

The ion capacity was determined by acidbase titration. The sulfonated sample was soaked in $0.1 \mathrm{M} \mathrm{NaOH}$ solution for 48 hours with the ratio of $25 \mathrm{~mL} \mathrm{NaOH}$ solution for 0.2 gram sample. Then the sample was titrated with $0.1 \mathrm{M} \mathrm{HCl}$. The ion capacity, $K_{i}$ was determined from the number of $\mathrm{Na}^{+}$which reacted with $-\mathrm{SO}_{3} \mathrm{H}$ grafted in the graphite surface using the following equation:

$K_{i}\left(\frac{\text { mmole equivalene }}{\text { gram sample }}\right)=\frac{\left(V_{\mathrm{NaOH}} \times N_{\mathrm{NaOH}}\right)_{\text {initial }}-\left(V_{\mathrm{HCl}} \times N_{\mathrm{HCl}}\right)_{\text {tiration }}}{\text { gram sulfonated graphite }}$

The sulfonated sample was used as a catalyst for the esterification of methyl acetate from acetic acid and methanol. The 96\% methanol was reacted with glacial acetic acid in the three-neck bottle equipped with a reflux con-
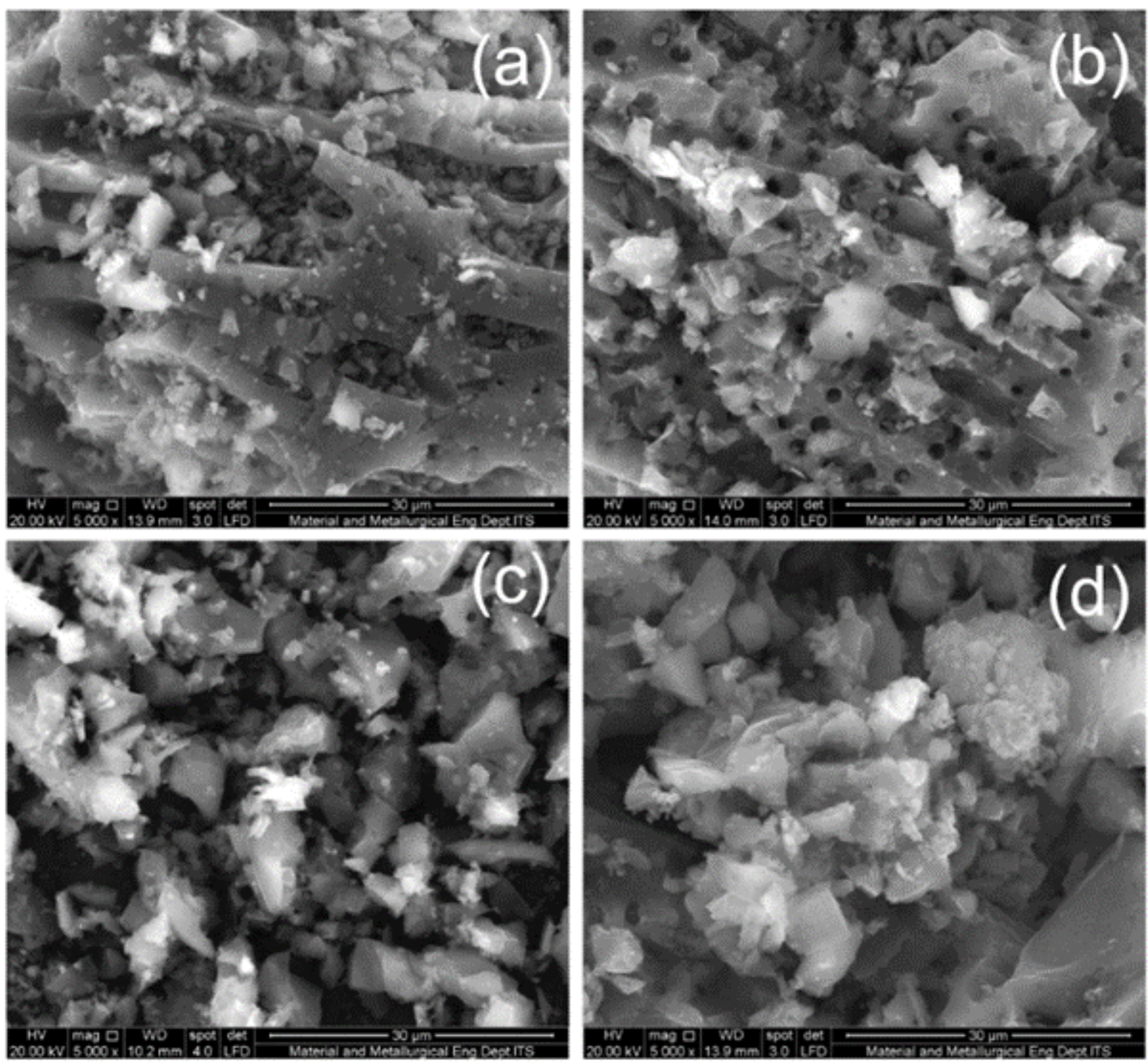

Figure 1. SEM images of (a) raw material (RM), graphite synthesized using RM:KOH weight ratio of (b) $1: 1$, (c) $1: 2$, and (d) $1: 4$. 
denser for three hours. The produced methyl acetate was purified with simple distillation. The distillate product was analyzed using GC to calculate the amount of methyl acetate. The yield of the produced methyl acetate was then calculated.

\section{Results and Discussions}

3.1 Effect of KOH Activation on the Generated Graphite Particles

Figure 1(a-d) shows the surface morphology of the samples by scanning electron microscopy (SEM) of raw material (RM), carbonized raw material $\mathrm{KOH}$ activated with $\mathrm{RM}: \mathrm{KOH}$ ratio of $1: 1,1: 2$, and $1: 4$, respectively. It can be seen that the surface morphology of raw material is a solid and irregular shape. Carbonization and activation made the raw material smaller in size with increasing the weight of $\mathrm{KOH}$ as an activated agent, as shown in Figures 1(b-d). Further examination on the surface area, pore size, and total volume are indicated by particle surface area analysis by BET and BJH methods.

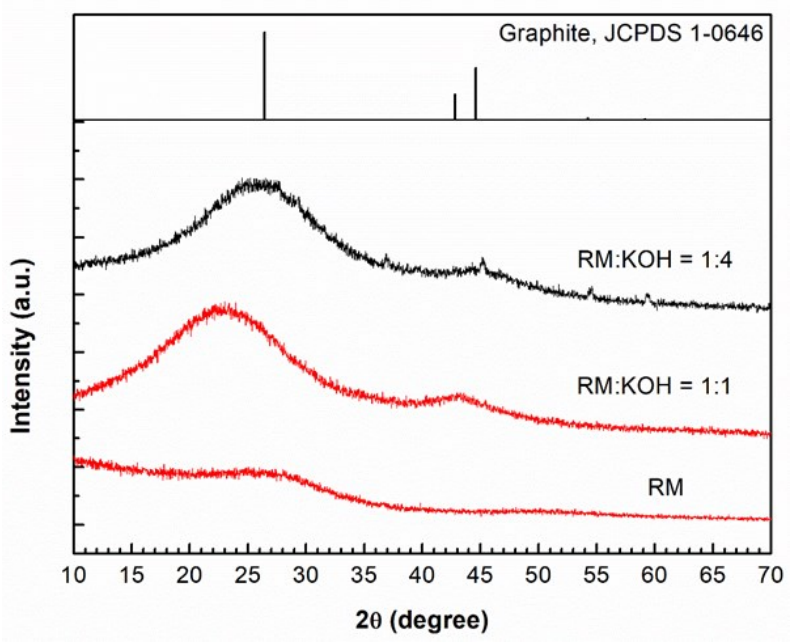

Figure 2. XRD pattern of raw material (RM), graphite synthesized using RM:KOH of $1: 1$ and $1: 4$.
Table 1 shows the surface area, average pore diameter, and pore volume total of raw material, carbonized and activated samples of $\mathrm{RM}: \mathrm{KOH}$ weight ratio of $1: 1,1: 2$, and 1:4. Following the SEM images, increasing the $\mathrm{KOH}$ weight as an activated agent led to an increase in the particle surface area. Using the Brunauer-Emmett-Teller (BET) method, the specific surface area increases significantly. The pore diameters determined by the Barrett-JoyderHalenda (BJH) desorption algorithm also indicated that the pore diameters increased with the increase of the weight of $\mathrm{KOH}$. RM: $\mathrm{KOH}$ weight ratio of $1: 2$ and 1:4 have pore diameters of 2.07 and $2.30 \mathrm{~nm}$ that were categorized to mesopores particles. Also, the total pore volume also increased with the increase of the weight of $\mathrm{KOH}$. Particles carbonized with $\mathrm{RM}: \mathrm{KOH}$ ratio of $1: 4$ resulted in the highest surface area and total pore volume, which characterized graphitic carbons. XRD analysis is needed for further examination in the graphitic R-ray diffraction patterns.

Figure 2 shows the X-Ray diffraction patterns of the raw material of coconut shell char-

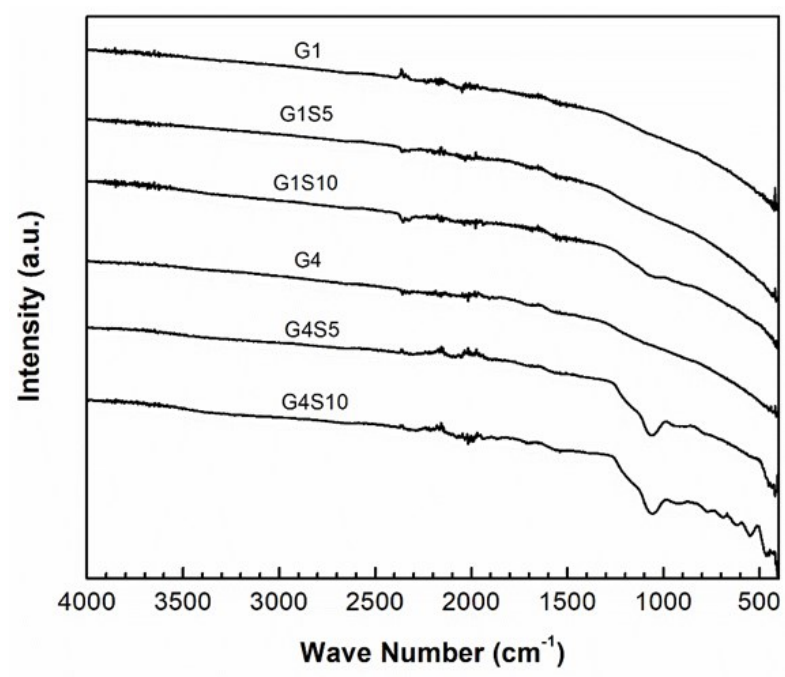

Figure 3. FTIR spectra of graphite and sulfonated graphite with duration 5 and 10 hours.

Table 1. BET surface areas, average pore diameter, and pore volume total of samples.

\begin{tabular}{lccc}
\hline & $\begin{array}{c}\text { Surface area } \\
\left(\mathrm{m}^{2} / \mathrm{g}\right)\end{array}$ & $\begin{array}{c}\text { Pore diameter } \\
(\mathrm{nm})\end{array}$ & $\begin{array}{c}\text { Total pore volume } \\
\left(\mathrm{cm}^{3} / \mathrm{g}\right)\end{array}$ \\
\hline Raw material $(\mathrm{RM})$ & 75.71 & 2.23 & 0.026 \\
$\mathrm{RM}: \mathrm{KOH}=1: 1(\mathrm{G} 1)$ & 554.84 & 0.57 & 0.079 \\
$\mathrm{RM}: \mathrm{KOH}=1: 2(\mathrm{G} 2)$ & 621.25 & 2.07 & 0.321 \\
$\mathrm{RM}: \mathrm{KOH}=1: 4(\mathrm{G} 4)$ & 1259.67 & 2.30 & 0.723 \\
\hline
\end{tabular}


coal (RM), graphite synthesized using RM:KOH of $1: 1$ and 1:4. They indicated the low crystallinity that increased with the carbonization treatment under nitrogen and the addition of $\mathrm{KOH}$ as an activated agent. The carbonization treatment and $\mathrm{KOH}$ activation led to the graphitization process of the raw material. It can be seen in the figure that the XRD pattern of the RM sample is a sloping peak. The carbonization treatment and the use of $\mathrm{KOH}$ as an activation agent with ratio $1: 1$ shows the significant peak intensity at $2 \theta$ centered at around $23.8^{\circ}$ that left-shifted for the highest peak of the graphite reference. The peak of the XRD pattern of RM:KOH $=1: 4$ at $26.5^{\circ}$ was the same as the graphite reference of JCPDS 10646 . The most intensive diffraction intensity of $2 \theta$ at $26.5^{\circ}$, can be indexed to (002) diffraction, which is the typical graphite carbons.

3.2 Effect of the Sulfonating Time on the Esterification Reaction

Before investigating the performance of the esterification reaction of acetic acid and methanol, the analysis of FTIR and ion capacity were carried out to investigate the bonds of the sulfonic group and the number of sulfonic ions, respectively, after sulfonating the graphite particles. Sulfonating time for 5 and 10 hours were compared. Figure 3 shows the FTIR spectra of graphite synthesized using RM:KOH ratio of 1:1 (G1) and 1:4 (G4). For G1, the sulfonic group of $-\mathrm{SO}_{3}$ bond was slightly observed after the G1 was sulfonated for 5 hours (G1S5) and increases slightly after increasing the sulfonation time for 10 hours (G1S10) at wave number around $1050 \mathrm{~cm}^{-1}$. On the other hand, the sul-
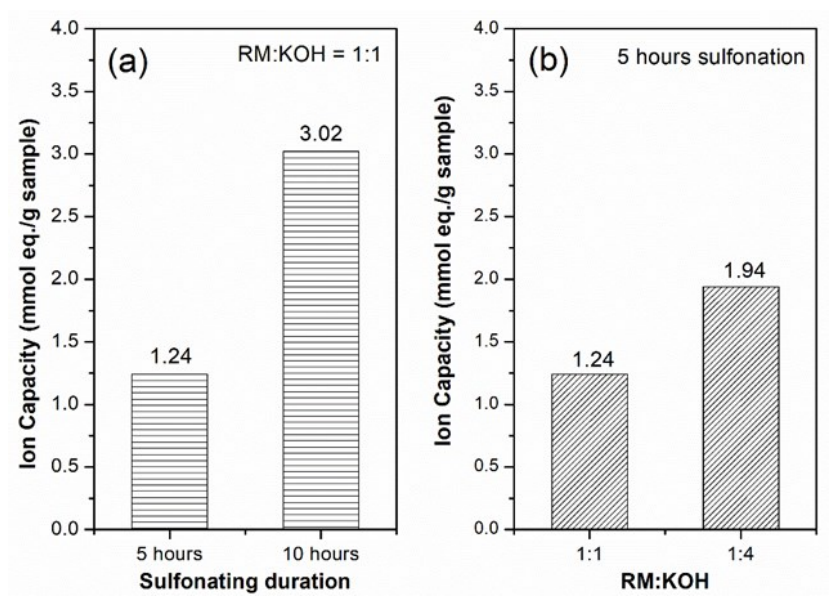

Figure 4. Ion capacities for (a) constant ratio of $\mathrm{RM}: \mathrm{KOH}$ and (b) constant sulfonating duration. fonic group of $-\mathrm{SO}_{3}$ bond clearly appeared after the G4 sample was sulfonated for 5 hours (G4S5), and the intensity was higher than that of G1S10. The intensity of the sulfonic group of $-\mathrm{SO}_{3}$ bond increased by increasing the sulfonating time to 10 hours (G4G10). The noticeable intensity of the sulfonic group of $-\mathrm{SO}_{3}$ bond correlated to the specific surface area of the samples. Increasing the specific surface area gives rise to the surface for bonding the sulfonic group. The ionic capacity calculated using Equation 1 also supported the FTIR results. As shown in Figure 4, increasing the sulfonating time and the weight of $\mathrm{KOH}$ led to an increase in the ionic capacity.

Figure 5 shows the effect of the RM:KOH ratio and the sulfonating time on the yield of methyl acetate. The yield of the reaction was affected by the number of $\mathrm{KOH}$ added to the raw material that increases with the increase of RM:KOH ratio for both sulfonating times of 5 and 10 hours. For 5 hours of sulfonating time, the yield increase from 32.62 to $85.00 \%$ by increasing the RM:KOH ratio from 1:1 to 1:4. Sulfonating time from 5 to 10 hours was also contributed to the increase of the yield from 85.00 to $96.57 \%$ for the case of graphite synthesized with RM:KOH = 1:4.

\section{Conclusions}

The graphitization of coconut shell charcoal was successfully synthesized for solid acid catalyst applications. The catalyst was examined for the esterification reaction of acetic acid and methanol. Carbonization of coconut shell charcoal was carried out by calcination under nitrogen flow and $\mathrm{KOH}$ activation. Graphite parti-

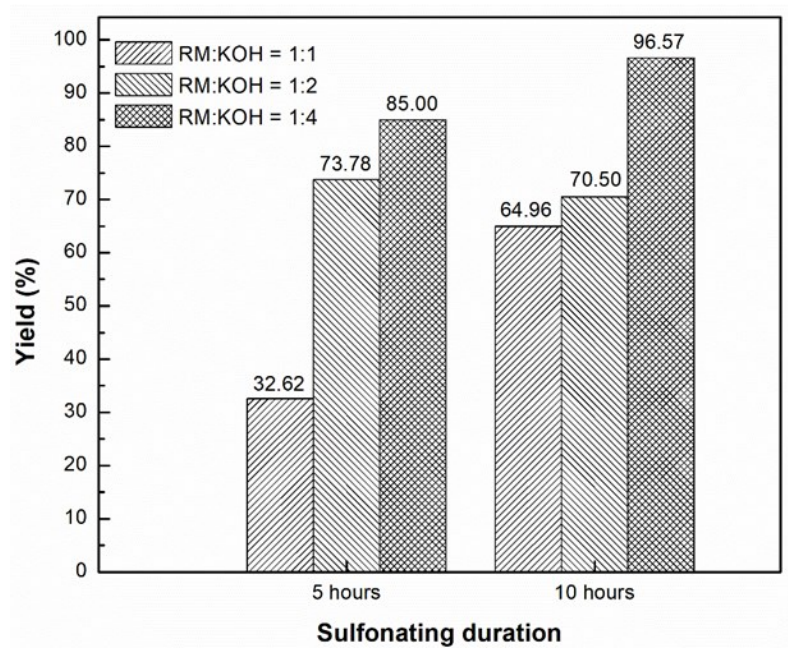

Figure 5. Yield of esterification reaction using synthesized catalysts at various RM: $\mathrm{KOH}$ ratio and sulfonating duration. 
cles as a result of the carbonization process were sulfonated by heating with the sulfuric acid. The highest yield was obtained by particles carbonized using RM:KOH ratio of $1: 4$ and 10 hours sulfonating time, reaching $96.57 \%$. This condition resulted in the highest specific surface area of $1259.67 \mathrm{~m}^{2} / \mathrm{g}$ with an average pore diameter of $2.30 \mathrm{~nm}$ and a total pore volume of $0.723 \mathrm{~cm}^{3} / \mathrm{g}$. The high surface area contributed to the high surface acid content. The surface acid was assigned as a sulfonic group $-\mathrm{SO}_{3}$ bond that the most intensity observed for particles carbonized using RM:KOH ratio of $1: 4$ and 10 hours sulfonating time.

\section{Acknowledgments}

Research Grant sponsored by Directorate of Research and Community Services, Directorate General of Strengthening Research and Development, Ministry of Research Technology and Higher Education, Republic Indonesia, is gratefully acknowledged. The authors also want to thank Ms. Fadhila Nur Fajri and Ms. Wenny May Rahardyanti for their assistance in the experiments.

\section{References}

[1] Jagadeeshbabu, P.E., Sandesh, K., Saidutta, M.B. (2011). Kinetics of esterification of acetic acid with methanol in the presence of ion exchange resin catalysts. Industrial and Engineering Chemistry Research, 50(12), 71557160. DOI: 10.1021/ie101755r

[2] Yu, W., Hidajat, K., Ray, A.K. (2004). Determination of adsorption and kinetic parameters for methyl acetate esterification and hydrolysis reaction catalyzed by Amberlyst 15 . Applied Catalysis A: General, 260(2), 191205. DOI: $10.1016 /$ j.apcata.2003.10.017

[3] Mekala, M., Goli, V.R. (2015). Kinetics of esterification of methanol and acetic acid with mineral homogeneous acid catalyst. Chinese Journal of Chemical Engineering, 23(1), 100105. DOI: $10.1016 /$ j.cjche.2013.08.002

[4] Tang, Z.E., Lim, S., Pang, Y.L., Ong, H.C., Lee, K.T. (2018). Synthesis of biomass as heterogeneous catalyst for application in biodiesel production: State of the art and fundamental review. Renewable and Sustainable Energy Reviews, 92, 235-253. DOI: 10.1016/j.rser.2018.04.056

[5] Borges, M.E., Díaz, L. (2012). Recent developments on heterogeneous catalysts for biodiesel production by oil esterification and transesterification reactions: A review. Renewable and Sustainable Energy Reviews, $16(5), \quad 2839-2849$. D O I : 10.1016/j.rser.2012.01.071
[6] Soltani, S., Rashid, U., Yunus, R., TaufiqYap, Y.H., Al-Resayes, S.I. (2016). Postfunctionalization of polymeric mesoporous C@Zn core-shell spheres used for methyl ester production. Renewable Energy, 99, 12351243. DOI: 10.1016/j.renene.2016.08.025

[7] Liu, Y., Lotero, E., Goodwin, J.G. (2006). A comparison of the esterification of acetic acid with methanol using heterogeneous versus homogeneous acid catalysis. Journal of Catalysis, $242(2), \quad 278-286$. DOI : 10.1016/j.jcat.2006.05.026

[8] Peters, T.A., Benes, N.E., Holmen, A., Keurentjes, J.T.F. (2006). Comparison of commercial solid acid catalysts for the esterification of acetic acid with butanol. Applied $\mathrm{Ca}$ talysis A: General, 297(2), 182-188. DOI: 10.1016/j.apcata.2005.09.006

[9] Tsai, Y.T., Lin, H.M., Lee, M.J. (2011). Kinetics behavior of esterification of acetic acid with methanol over Amberlyst 36. Chemical Engineering Journal, 171(3), 1367-1372. DOI: 10.1016/j.cej.2011.05.049

[10] Geng, L., Yu, G., Wang, Y., Zhu, Y. (2012). $\mathrm{Ph}$-SO $3 \mathrm{H}$-modified mesoporous carbon as an efficient catalyst for the esterification of oleic acid. Applied Catalysis A: General, 427-428, 137-144. DOI: 10.1016/j.apcata.2012.03.044

[11] Geng, L., Wang, Y., Yu, G., Zhu, Y. (2011). Efficient carbon-based solid acid catalysts for the esterification of oleic acid. Catalysis Communications, 13(1), 26-30. DOI: 10.1016/j.catcom.2011.06.014

[12] Guliani, D., Kaur, K., Singh, N., Sobti, A., Toor, A.P. (2019). Catalytic performance of sulfate-grafted graphene oxide for esterification of acetic acid with methanol. Chemical Engineering Communications, 206(5), 592604. DOI: $10.1080 / 00986445.2018 .1514601$

[13] Cheng, J., Qiu, Y., Huang, R., Yang, W., Zhou, J., Cen, K. (2016). Biodiesel production from wet microalgae by using graphene oxide as solid acid catalyst. Bioresource Technology, $221, \quad 344-349$. D O I : 10.1016/j.biortech.2016.09.064

[14] Allahresani, A., Nasseri, M.A., Akbari, A., Nasab, B.Z. (2015). Graphene oxide based solid acid as an efficient and reusable nanocatalyst for the green synthesis of diindolyloxindole derivatives in aqueous media. Reaction Kinetics, Mechanisms and Catalysis, 116(1), 249-259. DOI: 10.1007/s11144-0150883-7

[15] Chen, C.L., Huang, C.C., Ho, K.C., Hsiao, P.X., Wu, M.S., Chang, J.S. (2015). Biodiesel production from wet microalgae feedstock using sequential wet extraction/transesterification and direct transesteri- 
fication processes. Bioresource Technology, $194, \quad 179-186$. D O I : 10.1016/j.biortech.2015.07.021

[16] Na, S., Minhua, Z., Xiuqin, D., Lingtao, W. (2019). Preparation of sulfonated ordered mesoporous carbon catalyst and its catalytic performance for esterification of free fatty acids in waste cooking oils. RSC Advances, 9(28), 15941-15948. DOI: 10.1039/c9ra02546d

[17] Nata, I.F., Putra, M.D., Irawan, C., Lee, C.K. (2017). Catalytic performance of sulfonated carbon-based solid acid catalyst on esterification of waste cooking oil for biodiesel production. Journal of Environmental Chemical Engineering, 5(3), 2171-2175. DOI: 10.1016/j.jece.2017.04.029

[18] Yang, L., Yuan, H., Wang, S. (2019). Preparation and application of ordered mesoporous carbon-based solid acid catalysts for transesterification and epoxidation. Journal of Porous Materials, 26(5), 1435-1445. DOI: 10.1007/s10934-019-00742-w

[19] Chen, G., Fang, B. (2011). Preparation of solid acid catalyst from glucose-starch mixture for biodiesel production. Bioresource Technology, $102(3), \quad 2635-2640$. D O I : 10.1016/j.biortech.2010.10.099

[20] Fu, X.B., Chen, J., Song, X.L., Zhang, Y M., Zhu, Y., Yang, J., Zhang, C.W. (2015). Biodiesel production using a carbon solid acid catalyst derived from B-cyclodextrin. JAOCS, Journal of the American Oil Chemists' Society, 92(4), 495-502. DOI: 10.1007/s11746-0152621-8
[21] Janaun, J.A., Mey, T.J., Bono, A., Krishnaiah, D. (2017). Preparation and characterization of sugar based catalyst on various supports. Bulletin of Chemical Reaction Engineering \& Catalysis, 12(1), 41-48. DOI: 10.9767/bcrec.12.1.478.41-48

[22] Zeng, D., Zhang, Q., Chen, S., Liu, S., Wang, G. (2016). Synthesis porous carbon-based solid acid from rice husk for esterification of fatty acids. Microporous and Mesoporous Materials, $219, \quad 54-58$. D O I : 10.1016/j.micromeso.2015.07.028

[23] Song, X.L., Fu, X.B., Zhang, C.W., Huang, W.Y., Zhu, Y., Yang, J., Zhang, Y.M. (2012). Preparation of a novel carbon based solid acid catalyst for biodiesel production via a sustainable route. Catalysis Letters, 142(7), 869874. DOI: $10.1007 / \mathrm{s} 10562-012-0840-2$

[24] Yu, H., Niu, S., Lu, C., Li, J., Yang, Y. (2016). Preparation and esterification performance of sulfonated coal-based heterogeneous acid catalyst for methyl oleate production. Energy Conversion and Management, 126, 488-496. DOI: 10.1016/j.enconman.2016.08.036

[25] Fraga, A.C., Quitete, C.P.B., Ximenes, V.L., Sousa-Aguiar, E.F., Fonseca, I.M., Rego, A.M.B. (2016). Biomass derived solid acids as effective hydrolysis catalysts. Journal of Molecular Catalysis A: Chemical, 422, 248-257. DOI: 10.1016/j.molcata.2015.12.005 